\title{
ÍNDICE DE PREÇOS AO CONSUMIDOR EM VIÇOSA-MG: RESULTADOS DA PESQUISA DE ORÇAMENTOS FAMILIARES 2019/2020
}

\section{CONSUMER PRICE INDEX IN VIÇOSA-MG: THE RESULTS OF 2019/2020 FAMILY BUDGET SURVEY}

\author{
ÍNDICE DE PRECIOS AL CONSUMIDOR EM VIÇOSA-MG: RESULTADOS DE LA \\ INVESTIGACIÓN PRESUPUESTARIA FAMILIAR 2019/2020
}

\section{Resumo}

Jader Fernandes Cirino ${ }^{1}$

O Índice de Preços ao Consumidor de Viçosa (IPC-Viçosa) acompanha desde 1985, o comportamento dos preços e o custo da cesta básica no município de Viçosa, Minas Gerais (MG). Em virtude das alterações na cesta de consumo ao longo do tempo, é necessário realizar a atualização da mesma por meio de uma Pesquisa de Orçamentos Familiares (POF). Nesse sentido, uma vez que a última atualização havia sido feita em 2005/2006, realizou-se uma pesquisa de campo para tal fim, denominada POF 2019/2020, cujos principais resultados são apresentados neste artigo. ${ }^{2}$ A pesquisa foi conduzida no âmbito do projeto de extensão IPC-Viçosa, vinculado ao Departamento de Economia da Universidade Federal de Viçosa. A POF 2019/2020 definiu como populaçãoobjetivo, famílias com renda mensal de 1,01 a 6 salários mínimos e com 3 moradores, em média, por domicílio. 0 total de gastos com consumo dos entrevistados da população-objetivo tiveram as seguintes ponderações em termos de grupos de produtos: Alimentação (30,54\%), Vestuário (3,33\%), Habitação $(33,47 \%)$, Artigos de Residência $(1,23 \%)$, Transporte $(15,64 \%)$, Comunicação $(0,77 \%)$, Saúde e Cuidados Pessoais $(11,16 \%)$, Educação $(1,71 \%)$ e Despesas Pessoais (2,15\%).

Palavras-chave: Índice de Preços ao Consumidor. Pesquisa de Orçamentos Familiares. Viçosa-MG.

\section{Abstract}

Since 1985, the Consumer Price Index in the municipality of Viçosa, Minas Gerais (IPC-Viçosa) has followed the behavior of prices and the cost of the basic basket. Due to changes in the consumption basket over time, it is necessary to update it through a Family Budget Survey (POF). In this sense, since the last update had been made in 2005/2006, a survey was carried out for this purpose, called POF 2019/2020, whose main results are presented in this paper. The research was conducted within the scope of IPC-Viçosa extension project, linked to the Department of Economics of the Federal University of Viçosa. The POF 2019/2020 defined as target population, families with a monthly income of 1.01 to 6 minimum wages and with 3 residents, on average, per household. The total consumption expenditures of respondents in target population were weighted in terms of product groups: Food (30.54\%), Clothing (3.33\%), Housing (33.47\%), Household Items (1.23\%), Transportation (15.64\%), Communication (0.77\%), Health and Personal Care (11.16\%), Education (1.71\%) and Personal Expenses $(2.15 \%)$.

Keywords: Consumer Price Index. Family Budget Survey. Viçosa-MG.

\section{Resumen}

El Índice de Precios al Consumidor de Viçosa (IPC-Viçosa) ha estado monitoreando desde 1985, el comportamiento de los precios y el costo de la canasta básica en el municipio de Viçosa, Minas Gerais (MG). Debido a los cambios en la canasta de consumo a lo largo del tiempo, es necesario actualizarla a través de una Investigación Presupuestaria Familiar (POF). En este sentido, desde la última actualización realizada en 2005/2006, para ello se realizó una investigación de campo, denominada POF 2019/2020, cuyos principales

1. Doutor (2008) e Mestre (2005) em Economia Aplicada pela Universidade Federal de Viçosa (UFV) e Economista (2004) pela Universidade Federal de São João del-Rei. Atualmente é Professor Associado III do Departamento de Economia da UFV. É Coordenador do Programa de Pós-Graduação em Economia da UFV, no qual atua também como professor orientador. E-mail: jader.cirino@ufv.br Orcid: https://orcid.org/0000-0003-0543-2630

${ }^{2}$ Agradeço a FAPEMIG pelo financiamento da pesquisa. 
resultados se presentan em este artículo. La investigación se realizó en el ámbito del proyecto de extensión IPCViçosa, vinculado al Departamento de Economía de la Universidad Federal de Viçosa. La POF 2019/2020 define como famílias de población objetivo con un ingreso mensual de 1.01 a 6 salarios mínimos y com 3 residentes, en promedio, por hogar. Los gastos de consumo total de los encuestados en las famílias de población objetivo se ponderaron en términos de grupos de productos: alimentos (30.54\%), ropa (3.33\%), vivienda (33.47\%), artículos para el hogar ( $1.23 \%)$, Transporte $(15.64 \%)$, Comunicación $(0.77 \%)$, Salud y cuidado personal $(11.16 \%)$, Educación (1.71\%) y Gastos personales (2.15\%).

Palabras clave: Índice de Precios al Consumidor. Investigación Presupuestaria Familiar. Viçosa-MG.

\section{INTRODUÇÃO}

No Brasil, são calculados alguns índices de preços, uns locais, outros em âmbito nacional. Os autores Triches e Furlaneto (2005), Takamatsu e Lamounier (2006), Gorla, Oliveira e Lavarda (2010), BCB (2016), Uol (2019) e Sperandio (2020) apresentam os principais índices calculados no Brasil. Dentre esses, destaca-se o Índice de Preços ao Consumidor Amplo (IPCA), calculado pelo Instituto Brasileiro de Geografia e Estatística (IBGE). Tal índice tem abrangência nacional e é considerado pelo governo federal, a medida oficial da inflação no Brasil.

Entretanto, as variações de preços raramente se comportam de forma idêntica, posto que um índice nacional reflete uma média desses comportamentos, não representando adequadamente as especificidades regionais. Destaca-se que não se pode esperar que uma unidade consumidora residente no interior tenha a mesma estrutura de gastos de uma família residente numa grande região metropolitana. Despesas pessoais ou familiares com transporte urbano, comunicação, saúde, lazer, educação, alimentação fora do domicílio e mesmo vestuário terão, obviamente, ponderações comparativamente diferentes na cesta de consumo dessas duas famílias. Assim, não seria correto utilizar um índice de preços calculado para uma capital, ou mesmo para o Brasil, para entender o comportamento dos preços no interior. Isso porque tal metodologia desconsideraria as particularidades de consumo e da dinâmica de preços locais.

Tais diferenças foram também identificadas em estudos realizados por Gomes e Gomes (2002) e Lopes (2018). Os dois estudos compararam o índice de preços de Viçosa com um índice de preços de abrangência nacional.

No primeiro, os autores calcularam a variação estacional dos preços dos principais grupos de produtos no município de Viçosa-MG e nas capitais brasileiras que compõem o IPCBrasil da Fundação Getúlio Vargas, no período de janeiro de 1995 a dezembro de 2000. Os resultados indicaram que existem discrepâncias significativas entre o comportamento dos 
preços nos índices comparados, com padrões mais irregulares no comportamento dos preços no interior do que nas capitais.

Já no segundo, o autor verificou que no período compreendido entre janeiro de 2006 e dezembro de 2017, o IPC-Viçosa apresentou valores médios e desvios-padrão mais elevados para o índice geral e para todos os grupos de produtos, exceto Educação e Despesas Pessoais, na comparação com o IPCA.

Dessa forma, a construção de um índice de preços relativo a uma determinada região ou mesmo em nível local é de fundamental importância na medida em que auxilia o comportamento dos agentes econômicos locais, quer no papel de consumidor, quer como produtor ou prestador de serviços.

Outro problema que surge na confecção de um índice de preços é que, de tempos em tempos, verificam-se alterações na cesta de consumo das pessoas. Tal fato ocorre uma vez que, variando-se a renda e os preços relativos, os consumidores estarão sempre alterando a alocação de seus gastos e a participação relativa de cada item na despesa total. Desta forma, o ideal seria que em curtos períodos fossem estimados novos pesos através de pesquisas de orçamentos familiares. Entretanto, tal procedimento é inviabilizado, face aos altos custos de efetivação dessas pesquisas. Assim, o procedimento adotado tem sido o de estimar uma estrutura de gastos para um determinado período-base, utilizando-a como sistema de ponderações para um período relativamente longo, como forma de, indiretamente, diluir o custo da pesquisa para um período maior de vida útil de seus resultados.

Quando houver indícios de que a estrutura de gastos se modificou substancialmente, procede-se uma nova pesquisa, estimando nova estrutura de pesos.

O município de Viçosa tem experimentado grande desenvolvimento impulsionado pelo crescimento das atividades da Universidade Federal de Viçosa (UFV). Localizado no interior do estado de Minas Gerais (MG), o município tem como característica o fato de ser uma cidade universitária, uma vez que o comércio e os serviços locais estão fortemente voltados para o atendimento das demandas dos servidores e estudantes não só da UFV, como também das outras três instituições particulares de ensino superior existentes. Segundo dados apresentados por Maria, Faria e Stephan (2014), a população viçosense triplicou nos últimos 44 anos, passando de 25.784 habitantes em 1970 para 77.502 em 2014. Tal processo foi marcado por significativa urbanização do município, cuja população urbana passou de 65,9\% do total em 1970 para 93,2\% em 2014. Conforme IBGE (2020a), a população estimada para 2019 em Viçosa foi de 78.846 pessoas. 
Destaca-se ainda a presença de uma população flutuante de aproximadamente 20.000 habitantes, formada predominantemente por estudantes universitários, conforme destacam Maria, Faria e Stephan (2014). Nesse sentido, a oferta de bens e serviços aumentou e modificou-se qualitativamente, acompanhando o crescimento da cidade. São exemplos a instalação de supermercados nos bairros, a proliferação de sistemas de fast-food, o surgimento de inúmeros novos tipos de bens e serviços como os da área de lazer e comunicações e as novas modalidades de atendimento médico-hospitalar, a melhoria na estrutura de transporte urbano e muitos outros.

A possibilidade de adquirir novos bens e serviços certamente modifica o padrão de consumo da população, o qual é dinâmico ao longo do tempo. Nesse contexto, foi a realizada a IV Pesquisa de Orçamentos Familiares em Viçosa (POF 2019/2020) para identificar a nova realidade da estrutura de consumo e de oferta de bens e serviços no município. Através do conhecimento dessa nova realidade, é possível atualizar as ponderações dos bens e serviços para o cálculo do IPC-Viçosa que dessa forma, passa a refletir de maneira fidedigna, o comportamento do consumo e o impacto que as variações de preço nos bens e serviços provocam em tal consumo. Assim, o problema de pesquisa do presente artigo é a apresentação da POF 2019/2020 abordando a sua estratégia de aplicação assim como os seus resultados em termos do perfil socioeconômico da população viçosense e da estrutura de gastos de uma família típica do município de Viçosa - MG. Destaca-se que as informações da pesquisa foram coletadas apenas em famílias residentes no município, não considerando a parte da população flutuante composta por estudantes.

Em termos de objetivos, o artigo tem como objetivo geral analisar as informações da pesquisa de campo coordenada pelo autor do artigo, denominada POF 2019/2020, em termos de composição e características dos domicílios, assim como em relação à estrutura da distribuição da renda e dos dispêndios no município de Viçosa-MG. Especificamente, pretendese comparar os principais resultados da pesquisa de campo realizada com a POF 2005/2006, que foi a última realizada antes da POF 2019/2020, assim como com estudos a nível nacional e com a POF mais recente (2017/2018) que serve de referência para o cálculo do IPCA.

A pesquisa de campo que foi desenvolvida para providenciar a base de dados primária do presente artigo foi elaborada no âmbito do projeto de extensão IPC-Viçosa, o qual acompanha desde 1985, de forma ininterrupta, o comportamento mensal dos preços dos bens e serviços para os consumidores viçosenses. O mesmo teve origem em 1982, quando grupo de professores do então Departamento de Administração e Economia (DAE) da UFV perceberam a necessidade da criação de um índice de preços próprio para Viçosa que fosse 
capaz de captar as especificidades locais do comportamento de preços para os consumidores no município. Estando lotado na sala 133 do atual Departamento de Economia (DEE) da UFV, - IPC-Viçosa possui infraestrutura e equipe própria para a execução de suas atividades, além de contar com o apoio da Empresa Júnior de Economia e Serviços de Consultoria (EJESC) da UFV para o levantamento mensal in loco dos preços nos estabelecimentos comerciais de Viçosa. Os resultados e o boletim mensal do IPC-Viçosa são disponibilizados no site do projeto, disponível em DEE (2020). Além da POF 2019/2020, o IPC-Viçosa já realizou anteriormente três pesquisas dessa natureza: POF 1983/1984, POF 1991/1992 e POF 2005/2006.

\section{FUNDAMENTAÇÃO TEÓRICA: Pesquisas de Orçamentos Familiares e Índices de preços ao consumidor}

A POF é uma pesquisa que avalia as estruturas de consumo, de gastos, de rendimentos e parte da variação patrimonial das famílias. A partir dessas informações, é possível obter o padrão das condições de vida da população através da análise dos orçamentos domésticos. Adicionalmente, são obtidas também pela pesquisa, várias características dos domicílios e das famílias, incluindo a autoavaliação subjetiva sobre qualidade de vida. Os resultados da pesquisa permitem, ainda, analisar os gastos das famílias segundo as classes de rendimentos e a localização do domicílio, assim como a dimensão do mercado consumidor para grupos de produtos e serviços. A pesquisa tem como unidade de investigação o domicílio e é realizada por amostragem (IBGE, 2020b).

Especificamente para a POF 2019/2020, objeto do presente artigo, foram coletadas informações referentes à caracterização da população, assim como às rendas e despesas das unidades familiares. A pesquisa foi estruturada com base em IBGE (2020b), de forma que a pesquisa para Viçosa fosse elaborada e conduzida nos mesmos moldes da POF nacional desenvolvida pelo IBGE para a ponderação do IPCA.

Com respeito às características da população, as principais informações coletadas foram as seguintes: a) Composição familiar; b) Idade e sexo dos componentes; c) Grau de instrução; d) Características dos domicílios e condições de moradia; e) Qualidade de serviços essenciais; f) Qualidade de vida; g) Origem e composição da renda familiar e; h) Despesas da família.

A renda familiar é entendida como sendo o somatório de todos os rendimentos recebidos pelos membros da família, a qual constitui a unidade de consumo. As despesas, por sua vez, compreendem um somatório dos gastos coletivos das famílias, tais como aluguel e demais gastos com moradia, alimentação, lazer e os gastos individuais de seus membros, dentre os 
quais se destacam vestuário, transporte, despesas pessoais, entre outros, conforme ressaltam IBGE (2020b) e Gomes (2006).

Para o cálculo do IPC-Viçosa, assim como para o IPCA, as despesas com bens e serviços das famílias obtidas a partir das respectivas POF são agrupadas nos seguintes grupos de consumo: i) Alimentação e bebidas: cereais, carnes, gorduras, laticínios, açúcares e doces, bebidas, hortifrutigranjeiros, condimentos, alimentação fora do lar, etc.; ii) Vestuário: roupas masculinas e femininas, calçados, etc.; iii) Habitação: aluguel, condomínio, serviços domésticos, reparos e consertos, impostos, material de limpeza, etc.; iv) Artigos de residência: móveis, utensílios, utilidades domésticas, eletrodomésticos, etc.; v) Transporte: transporte coletivo, táxi, veículos, manutenção, combustíveis, etc.; vi) Comunicação: telefone, correio, etc.; vii) Saúde e cuidados pessoais: remédios, assistência médica e dentária, higiene pessoal, etc.; viii) Educação: mensalidades, taxas escolares e material escolar e; ix) Despesas pessoais: serviços pessoais, lazer, cultura, etc.

Feita esta classificação para os produtos componentes da cesta de mercadorias com seus respectivos gastos, pode-se dar início à fase seguinte, que é a definição das estruturas de peso. A partir do conjunto de produtos com seus respectivos custos, obtém-se o gasto médio das famílias com cada produto o que, totalizando, representará o custo médio da cesta. A estrutura de ponderação, ou seja, o peso de cada grupo na cesta é a participação percentual do seu custo no custo total da cesta. Deste modo, o somatório dos pesos de todos os grupos resultará no valor igual a $100 \%$.

Essa ponderação é indispensável para o cálculo de um índice geral de preços que leve em consideração a importância econômica de cada mercadoria, que é dada pelo valor monetário da quantidade vendida de cada produto, ou seja, o gasto médio das famílias com cada produto fornecido pela POF. Com tal procedimento, tem-se um índice ponderado de preço, cujos pesos por produto são os gastos médios das famílias para cada produto divididos pelo gasto médio total das famílias. Essa forma de cálculo, a qual é utilizada pelo IPC-Viçosa, é denominada índice de preços de Laspeyres (HOFFMANN, 2006). Matematicamente, o referido índice é calculado conforme segue:

$$
I_{L}\left(p_{t} \mid p_{0}\right)=\frac{\sum_{i=1}^{n}\left(\frac{P_{i t}}{P_{i 0}}\right)\left(P_{i 0} Q_{i 0}\right)}{\sum_{i=1}^{n} P_{i 0} Q_{i 0}}
$$

Onde:

$I_{L}=$ índice de Laspeyres

$P_{i t}=$ Preço da $i$ - ésima mercadoria no período $t$ 
$P_{\text {io }}=$ Preço da $i$ - ésima mercadoria no período base

$Q_{i 0}=Q$ uantidade da $i$ - ésima mercadoria vendida no período base

Simplificando, tem-se:

$$
I_{L}\left(\boldsymbol{p}_{t} \mid \boldsymbol{p}_{0}\right)=\frac{\sum_{i=1}^{n} P_{i t} Q_{i 0}}{\sum_{i=1}^{n} P_{i 0} Q_{i 0}}
$$

A interpretação econômica do referido índice é a comparação do custo de aquisição da cesta de mercadoria no período t com o custo de aquisição dessa mesma cesta de mercadoria no período base. Essa cesta é o valor monetário, aos preços do período base, do conjunto ou vetor das quantidades vendidas no período-base, que é exatamente o denominador na equação (2), sendo obtido através da POF por meio do somatório do gasto médio das famílias com cada um dos bens e serviços adquiridos e apontados na referida pesquisa.

\section{PROCEDIMENTOS METODOLÓGICOS: Área de estudo, análise exploratória e fonte de dados}

O município de Viçosa está localizado na mesorregião da Zona da Mata de Minas Gerais, região Sudeste do Estado, dentro da microrregião de Viçosa. Com área de 300,15 Km², é limitado pelos municípios de Teixeiras e Guaraciaba ao norte; Paula Cândido e Coimbra ao sul; Cajuri e São Miguel do Anta a leste e Porto Firme a oeste (Fig. 1).

Figura 1 - Localização geográfica do município de Viçosa, Minas Gerais 


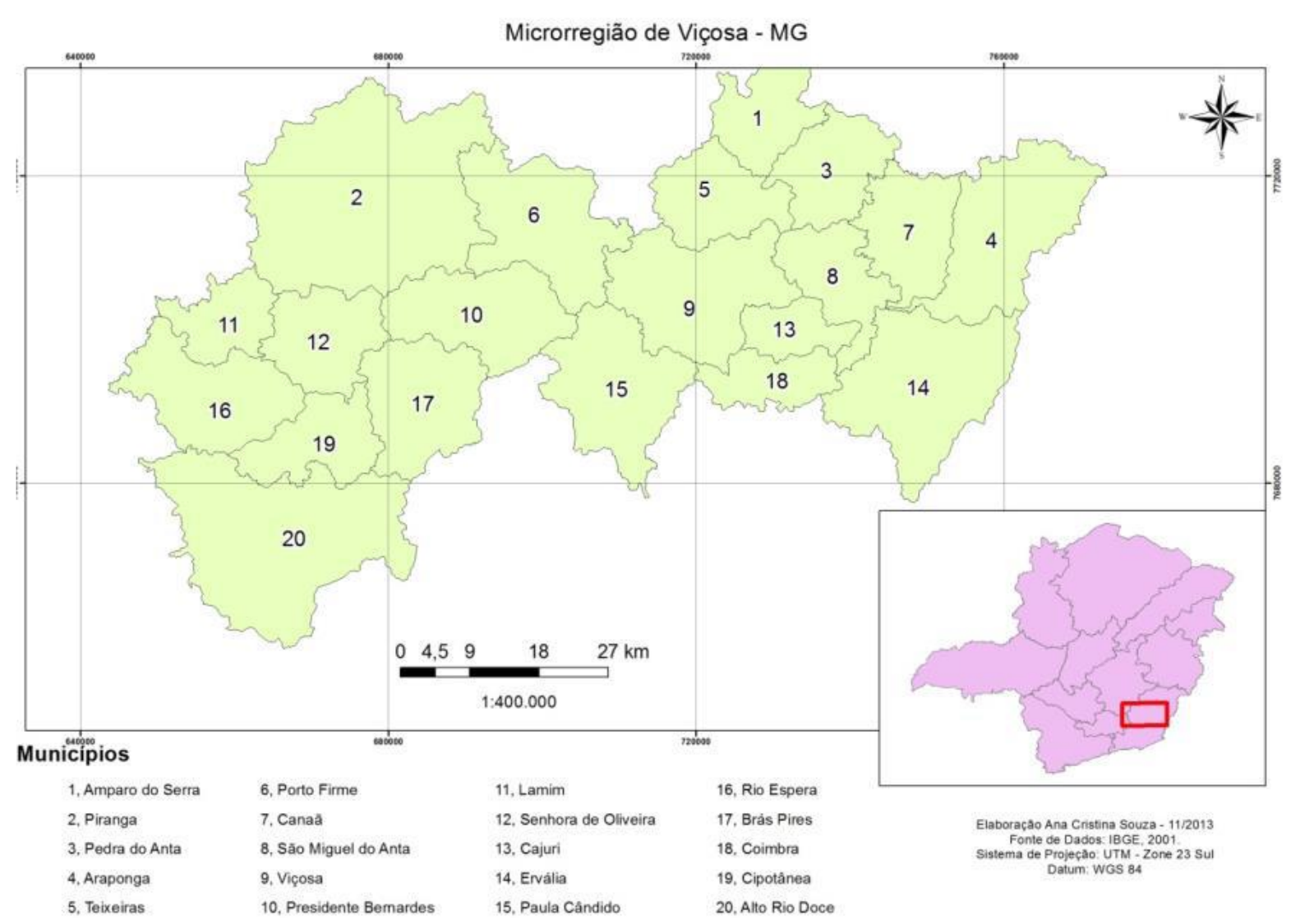

Fonte: Maria, Faria e Stephan (2014, p. 42).

A seguir apresenta-se breve diagnóstico socioeconômico do município com base em Cruz (2014) e Maria, Faria e Stephan (2014). Conforme já apontado, Viçosa caracteriza-se como uma cidade universitária, não só pela relevância das suas instituições de ensino, como também pela interdependência do município e da economia local com a UFV e as demais instituições de ensino.

Adicionalmente, Viçosa é um polo regional de dezenas de outras cidades menores, além de lugarejos, vilas e pequenas comunidades, de onde se deslocam seus moradores, produtores rurais e pequenos comerciantes, na demanda por variados bens e serviços, uma vez que o município se destaca nas atividades urbanas de comércio e serviços. Segundo IBGE (2020a), esse setor representava 65\% do Produto Interno Bruto (PIB) do munícipio em 2017, sendo tais valores para agropecuária, indústria e setor público de respectivamente, 1\%, 11\% e $23 \%$.

No que se refere à atividade industrial, o município possui empresas de destaque no ramo de vacinas e de produtos de cabelo, assim como na construção civil, setor moveleiro e serralherias. Em relação à agropecuária, a produção de café, milho, feijão, bovinos, suínos e frangos de corte, desenvolvida em propriedades de pequeno e médio porte, são as mais 
importantes.

O perímetro urbano é bem servido pelas redes de água e energia elétrica, embora apenas razoavelmente pelo serviço de captação pluvial e esgotos, principalmente nas áreas novas, habitadas por famílias de menor poder aquisitivo.

Segundo IBGE (2020a), para o ano de 2017, Viçosa apresentou PIB per capita de $\mathrm{R} \$ 19.869,94$, sendo o $1^{\circ}$ da microrregião, o $227^{\circ}$ do estado e $02.301^{\circ}$ do país. Para o mesmo ano, o salário médio mensal de trabalhadores formais foi de 3,2 , sendo $01^{\circ}$ da microrregião, 0 $11^{\circ}$ do estado e o 109ํ do país. De acordo com PNUD, FJP e IPEA (2013), o Índice de Desenvolvimento Humano Municipal (IDHM) foi de 0,775 em 2010, situando o município na faixa de Desenvolvimento Humano Alto (IDHM entre 0,700 e 0,799). Em termos nacionais, Viçosa ocupa a 178 17 posição entre os 5.565 municípios brasileiros. A dimensão que mais contribuiu para o IDHM do município foi Longevidade $(0,883)$, seguida de Renda $(0,758)$ e Educação $(0,696)$.

Partindo agora para a metodologia do trabalho, foi utilizada a análise exploratória de dados para analisar o perfil socioeconômico da população e da estrutura de gastos de uma família típica do município de Viçosa - MG. Essa metodologia, que também foi utilizada na POF anterior, é definida por Sicsú e Dana (2012) e Jelihovschi (2014) como um conjunto de métodos que permitem o estudo detalhado de dados com a finalidade de obter deles a maior quantidade possível de informação. Dito de outra forma, tal análise utiliza ferramentas estatísticas, como gráficos, tabelas, medidas de tendência central e de variabilidade para investigar o conjunto de dados de forma a compreender as suas características fundamentais. Neste estudo, a referida análise foi feita por meio do software Stata 15, ao passo que na POF 2005/2006, fora utilizado o software Excel na versão mais recente à época.

Os dados do artigo foram obtidos através de pesquisa de campo conduzida e coordenada pelo autor do presente artigo, a qual deu origem à POF 2019/2020. A pesquisa foi conduzida no contexto do projeto de extensão IPC-Viçosa, vinculado ao Departamento de Economia da UFV. Entretanto, além desse artigo, a POF 2019/2020 gerou relatório de pesquisa (CIRINO, 2020) que apresenta o questionário e todos os detalhes e procedimentos metodológicos da pesquisa em questão.

A população estudada pela pesquisa de campo abrangeu todos os domicílios familiares com menos de quatro unidades de consumo (ou seja, quatro famílias residindo em uma mesma moradia), localizados na zona urbana do município de Viçosa, MG, não sendo entrevistadas as habitações coletivas tais como pensões, repúblicas de estudantes, asilos e hospitais. A partir da definição dessa população, foi feita uma amostragem estratificada pelos bairros do 
município de Viçosa. O critério adotado foi que o número de questionários aplicados em cada bairro seguisse a distribuição dos imóveis registrados no cadastro do Imposto Predial Territorial Urbano (IPTU) disponibilizado pela Prefeitura Municipal de Viçosa. Dessa forma, distribuíramse os questionários relativamente à quantidade de imóveis em cada bairro, de forma que os bairros estivessem representados na amostra conforme a sua participação no universo total. Assim, o bairro Centro, por exemplo, cujo total de domicílios representava $20,5 \%$ do total de domicílios de Viçosa, teve a aplicação de 63 questionários, ou seja, 20,5\% dos 307 questionários aplicados. Esse último número foi obtido por meio de critério estatístico que garantiu a representatividade da população por meio da amostra obtida com $90 \%$ de confiabilidade.

É importante destacar que a amostra total foi dividida em 6 sub-amostras de mesmo tamanho, sendo as entrevistas realizadas entre novembro de 2019 e abril de 2020, após aprovação em 18 de outubro de 2019 do Comitê de Ética em Pesquisa com Seres Humanos da UFV (CEP) por meio do Parecer 3.649.275. Destaca-se que não se repete o questionário em uma mesma família e que a coleta de informações em períodos distintos do tempo foi importante para captar possíveis diferenças sazonais de consumo.

\section{RESULTADOS E ANÁLISES: perfil socioeconômico, características e estrutura da renda e dispêndios das famílias e domicílios de Viçosa-MG a partir da POF 2019/2020}

De acordo com os dados da TAB. 1, o número máximo de moradores nos domicílios entrevistados foi de 8 moradores por domicílio. De modo geral, a maioria dos domicílios é composta por 2 a 4 moradores, sendo os de maiores frequências os domicílios com 2 e 3 moradores, respectivamente. A média foi de 2,77 moradores por domicílio, com mediana de 3 moradores por domicílio.

Tabela 1 - Distribuição da amostra segundo o número de moradores por domicílio, POF 2019/2020, Viçosa, MG

\begin{tabular}{ccc}
\hline Número de moradores por & \multicolumn{2}{c}{ Domicílios } \\
\cline { 2 - 3 } domicílio & № & $\%$ \\
\hline 1 & 31,00 & 10,10 \\
2 & 109,00 & 35,49 \\
3 & 90,00 & 29,32 \\
4 & 48,00 & 15,64 \\
5 & 18,00 & 5,86 \\
6 & 1,00 & 0,33 \\
\hline
\end{tabular}




\begin{tabular}{ccc}
\hline 7 & 3,00 & 0,98 \\
8 & 1,00 & 0,33 \\
Sem declaração & 6,00 & 1,95 \\
\hline Total & 307,00 & 100,00 \\
\hline
\end{tabular}

Fonte: Do autor.

Na POF anterior (2005/2006), o valor médio encontrado foi de 3,86, sendo que na POF 1991/1992, tal valor fora de 4,52 moradores por domicílio. A redução do número de pessoas por domicílio reflete as mudanças recentes ocorridas na composição familiar do brasileiro, cuja principal mudança é a redução do número de filhos. Segundo UNFPA (2018), o Brasil vem apresentando queda acentuada da taxa de fecundidade. O número médio de filhos por mulher que era de 2,85 em 1991, passou para 2,39 em 2000, 1,87 em 2010 e 1,7 em 2015. Destacase que essa diminuição do número de filhos foi observada em todas as regiões do país e extratos sociais. O referido estudo apontou que o acesso aos serviços de saúde e à informação, além do processo de urbanização e melhoria de renda, são os fatores responsáveis pela tendência de queda verificada.

No mesmo sentido, comparando-se com a POF anterior, percebe-se que aumentou o número de residências em que moram poucas pessoas. Em 2005/2006, em 18,21\% dos domicílios entrevistados residiam até duas pessoas. Em 2019/2020, esse número é de 45,59\% dos domicílios, sendo inclusive 2 moradores por domicílio a moda da amostra. Por outro lado, há menor quantidade de famílias grandes. Na POF atual, em 23,14\% dos domicílios entrevistados residiam 4 ou mais pessoas, enquanto na POF anterior, este número era de $58,69 \%$.

Em relação ao gênero, para os moradores com informação sobre essa característica, observou-se que o número de homens e mulheres foi praticamente o mesmo, sendo esse de respectivamente, 396 e 395. Na POF anterior, o número de mulheres havia sido maior do que o de homens, representado $53 \%$ do total.

$\mathrm{Na}$ TAB. 2, encontra-se a distribuição da população entrevistada por grupos de escolaridade e gênero para os moradores cujas essas informações foram declaradas.

Tabela 2 - Distribuição da população por grupos de escolaridade e gênero, POF 2019/2020, Viçosa, MG

\begin{tabular}{ccccccc}
\hline \multirow{2}{*}{$\begin{array}{c}\text { Nível de } \\
\text { instrução }\end{array}$} & \multicolumn{3}{c}{ Sexo } & \multicolumn{2}{c}{ Total } \\
\cline { 2 - 5 } & \multicolumn{2}{c}{ Masculino } & \multicolumn{3}{c}{ Feminino } & № \\
\hline Sem instrução & 3 & $0,78 \%$ & 6 & $1,61 \%$ & 9 & $1,19 \%$ \\
Ed. ${ }^{1}$ Infantil & 14 & $3,66 \%$ & 10 & $2,69 \%$ & 24 & $3,18 \%$ \\
Fund. ${ }^{2}$ 10 ao 30 & 15 & $3,92 \%$ & 15 & $4,03 \%$ & 30 & $3,97 \%$
\end{tabular}




\begin{tabular}{ccccccc} 
Fund. 40 ao 5o & 34 & $8,88 \%$ & 45 & $12,10 \%$ & 79 & $10,46 \%$ \\
Fund. 6o ao 8ㅇ & 20 & $5,22 \%$ & 22 & $5,91 \%$ & 42 & $5,56 \%$ \\
Fund. completo & 29 & $7,57 \%$ & 28 & $7,53 \%$ & 57 & $7,55 \%$ \\
Médio inc. $^{3}$ & 33 & $8,62 \%$ & 24 & $6,45 \%$ & 57 & $7,55 \%$ \\
Médio completo $^{\text {EJA }}$ & 90 & $23,50 \%$ & 83 & $22,31 \%$ & 173 & $22,91 \%$ \\
Eup. $^{5}$ inc. & 1 & $0,26 \%$ & 4 & $1,08 \%$ & 5 & $0,66 \%$ \\
Sup. completo & 28 & $7,31 \%$ & 27 & $7,26 \%$ & 55 & $7,28 \%$ \\
Técnico & 18 & $20,63 \%$ & 78 & $20,97 \%$ & 157 & $20,79 \%$ \\
Espec. $/$ MBA & 2 & $4,70 \%$ & 6 & $1,61 \%$ & 24 & $3,18 \%$ \\
Mestrado & 13 & $0,52 \%$ & 5 & $1,34 \%$ & 7 & $0,93 \%$ \\
Doutorado & 4 & $3,39 \%$ & 17 & $4,57 \%$ & 30 & $3,97 \%$ \\
\hline Total & 383 & $1,04 \%$ & 2 & $0,54 \%$ & 6 & $0,79 \%$ \\
\hline
\end{tabular}

Legenda: ${ }^{1}$ Educação. ${ }^{2}$ Fundamental. ${ }^{3}$ Incompleto. ${ }^{4}$ Educação de Jovens e Adultos. ${ }^{5}$ Superior.

${ }^{6}$ Especialização. ${ }^{7}$ Master of Business Administration.

Fonte: Do autor.

Destaca-se que não há diferença significativa entre os sexos em termos de nível de instrução. Percebe-se também que os dados confirmam a vocação de cidade educadora de Viçosa, uma vez que para ambos os sexos, a maior parte das pessoas tem ensino médio completo ou ensino superior completo ${ }^{3}$. Inclusive, a participação desses dois níveis de instrução em relação ao total apresentou aumento considerável na comparação com a POF 2005/2006, reflexo da expansão da UFV e das instituições privadas de ensino superior localizadas no município.

Na TAB. 3, encontra-se a distribuição da pessoa de referência do domicílio por gênero e nível de instrução. Embora o número de famílias chefiadas por homens continue sendo maioria $(59,01 \%$ contra $40,99 \%$ para as mulheres), a diferença entre os sexos diminuiu significativamente entre a POF anterior e a atual. Enquanto na primeira a vantagem em favor dos homens nesse aspecto era de 45,66 pontos percentuais, na segunda essa é de 18,02 pontos percentuais. Esse resultado vai ao encontro do aumento das famílias chefiadas por mulheres verificado no Brasil. Segundo Cavenaghi e Alves (2018), as famílias chefiadas por homens diminuíram de 72,6\% em 2001 para 59,5\% em 2015, enquanto o percentual de famílias chefiadas por mulheres subiu de $27,4 \%$ para $40,5 \%$ no mesmo período, ou seja, números muito próximos aos verificados pelo presente estudo em Viçosa.

Tabela 3 - Distribuição da pessoa de referência no domicílio por grupos de escolaridade e gênero, POF 2019/2020, Viçosa, MG

\begin{tabular}{lll}
\hline Nível de & Sexo & Total \\
\hline
\end{tabular}

\footnotetext{
${ }^{3}$ Essa vocação fica clara na comparação com a realidade do Brasil como um todo. De acordo com IBGE (2020e), $52,6 \%$ da população com 25 anos ou mais no país ainda não havia completado o ensino médio em 2018 , sendo que para os entrevistados na presente pesquisa em Viçosa, tal valor fora de $40,12 \%$.
} 


\begin{tabular}{|c|c|c|c|c|c|c|}
\hline \multirow[t]{2}{*}{ instrução } & \multicolumn{2}{|c|}{ Masculino } & \multicolumn{2}{|c|}{ Feminino } & \multirow[b]{2}{*}{ № } & \\
\hline & № & & № & & & \\
\hline Sem instrução & 0 & $0,00 \%$ & 1 & $0,86 \%$ & 1 & $0,35 \%$ \\
\hline Ed. ${ }^{1}$ Infantil & 0 & $0,00 \%$ & 1 & $0,86 \%$ & 1 & $0,35 \%$ \\
\hline Fund. $^{2}$ 1을 3 은 & 4 & $2,40 \%$ & 7 & $6,03 \%$ & 11 & $3,89 \%$ \\
\hline Fund. 40 ao 5o & 9 & $5,39 \%$ & 16 & $13,79 \%$ & 25 & $8,83 \%$ \\
\hline Fund. 6o ao 8ㅇ & 3 & $1,80 \%$ & 3 & $2,59 \%$ & 6 & $2,12 \%$ \\
\hline Fund. completo & 18 & $10,78 \%$ & 6 & $5,17 \%$ & 24 & $8,48 \%$ \\
\hline Médio inc. ${ }^{3}$ & 9 & $5,39 \%$ & 4 & $3,45 \%$ & 13 & $4,59 \%$ \\
\hline Médio completo & 33 & $19,76 \%$ & 33 & $28,45 \%$ & 66 & $23,32 \%$ \\
\hline $\mathrm{EJA}^{4}$ & 1 & $0,60 \%$ & 2 & $1,72 \%$ & 3 & $1,06 \%$ \\
\hline Sup. ${ }^{5}$ inc. & 3 & $1,80 \%$ & 6 & $5,17 \%$ & 9 & $3,18 \%$ \\
\hline Sup. completo & 57 & $34,13 \%$ & 24 & $20,69 \%$ & 81 & $28,62 \%$ \\
\hline Técnico & 15 & $8,98 \%$ & 2 & $1,72 \%$ & 17 & $6,01 \%$ \\
\hline Espec. $6 / \mathrm{MBA}^{7}$ & 0 & $0,00 \%$ & 1 & $0,86 \%$ & 1 & $0,35 \%$ \\
\hline Mestrado & 11 & $6,59 \%$ & 9 & $7,76 \%$ & 20 & $7,07 \%$ \\
\hline Doutorado & 4 & $2,40 \%$ & 1 & $0,86 \%$ & 5 & $1,77 \%$ \\
\hline Total & 167 & $100,00 \%$ & 116 & $100,00 \%$ & 283 & $100,00 \%$ \\
\hline
\end{tabular}

Legenda: ${ }^{1}$ Educação. ${ }^{2}$ Fundamental. ${ }^{3}$ Incompleto. ${ }^{4}$ Educação de Jovens e Adultos. ${ }^{5}$ Superior.

${ }^{6}$ Especialização. ${ }^{7}$ Master of Business Administration.

Fonte: Do autor

Diferentemente do que foi verificado para a população como um todo, no recorte para a pessoa de referência, nota-se diferenças por gênero no que tange aos grupos de escolaridade. Enquanto para os homens, a maioria deles encontra-se primeiro no nível superior completo e segundo no médio completo, tal situação é o contrário para as mulheres, indicando que neste recorte, eles apresentam comparativamente maior nível educacional do que elas. De qualquer forma, assim como ocorrera para a população como um todo, também para as pessoas de referência no domicílio, Viçosa apresenta elevado nível educacional.

Com o objetivo de associar o rendimento médio do domicílio com o nível de instrução por gênero, apresenta-se a TAB. 4.

Tabela 4 - Rendimento familiar médio, em salários mínimos, por nível de instrução e gênero da pessoa de referência no domicílio, POF 2019/2020, Viçosa, MG

\begin{tabular}{ccc}
\hline & \multicolumn{2}{c}{ Gênero } \\
\cline { 2 - 3 } Nível de instrução & Masculino & Feminino \\
\hline Fundamental completo & 4,58 & 2,23 \\
Ensino médio completo & 8,18 & 4,69 \\
Ensino superior completo & 4,99 & 12,79 \\
Pós-graduação completa & 14,34 & 14,16 \\
\hline
\end{tabular}

Fonte: Do autor.

Para as mulheres, observa-se claramente relação direta entre escolaridade e rendimento, apontada pela literatura por vários trabalhos como os de Hoffmann e Simão (2005), Van Zaist, Nakabashi e Salvato (2010) e Cirino (2018). Já para os homens, a mesma só 
não foi verificada na passagem do ensino médio completo para o superior completo, embora as pessoas de referência do sexo masculino com pós-graduação tenham apresentado rendimento domiciliar médio superior a todos os níveis de instrução inferiores. Na comparação entre os sexos, as mulheres só superaram os homens no nível superior completo, indicando que de maneira geral, assim como encontrado na POF 2005/2006, os domicílios chefiados por eles tendem a apresentar maior rendimento do que aqueles no qual elas são a pessoa de referência. Esse último ponto pode estar relacionado às dificuldades que são enfrentadas principalmente pelas mulheres chefes do domicílio no que tange ao acesso a melhores postos de trabalho e disponibilidade de escolas e creches. Além disso, tem-se ainda a existência da discriminação salarial por gênero que atinge a todas as mulheres no país, conforme destacado por Cirino (2018).

Passando para a faixa etária dos entrevistados, a TAB. 5 apresenta a distribuição desses últimos por grupos de idade declarada. Verifica-se que a população de Viçosa é relativamente jovem, sendo que $53,01 \%$ das pessoas tem idade inferior a 41 anos e que a maior concentração dos entrevistados foi encontrada no grupo etário de 21 a 30 anos. A média de anos encontrada foi de 40,3. No entanto, na comparação com a POF 2005/2006, houve envelhecimento da população em estudo, já que naquela pesquisa, a referida média fora de 33,6 anos.

Tabela 5 - Distribuição da população por grupos de idade, POF 2019/2020, Viçosa, MG

\begin{tabular}{ccc}
\hline Grupos de idade & Número & $\%$ \\
\hline 00 a 10 anos & 47 & 6,14 \\
11 a 20 anos & 109 & 14,23 \\
21 a 30 anos & 138 & 18,02 \\
31 a 40 anos & 112 & 14,62 \\
41 a 50 anos & 99 & 12,92 \\
51 a 60 anos & 115 & 15,01 \\
61 a 70 anos & 79 & 10,31 \\
> de 70 anos & 67 & 8,75 \\
\hline Total & 766 & 100,00 \\
\hline
\end{tabular}

Fonte: Do autor.

No mesmo sentido, destaca-se o aumento do número de pessoas com idade superior a 60 anos. Na POF atual, a porcentagem dessa faixa é de 19,06\%, enquanto na POF anterior, tal valor era de 13,15\%. Esse fenômeno de envelhecimento da população viçosense reflete as melhorias na qualidade de vida, principalmente em questões relacionadas à saúde, as quais impactam positivamente no aumento dos anos de vida. Ademais, esse resultado está de 
acordo com os dados do Brasil para a expectativa de vida ao nascer a qual, segundo IBGE (2019), aumentou de 69,8 anos em 2000 para 73,9 em 2010, até atingir 76,3 anos em 2018.

A seguir, a TAB. 6 apresenta os dados relacionados às características dos domicílios investigados.

Tabela 6 - Características dos domicílios, POF 2019/2020, Viçosa, MG

\begin{tabular}{ccr}
\hline Tipo & Número & $\%$ \\
\hline Apartamento & 112 & 36,48 \\
Casa não rústica & 107 & 34,85 \\
Casa rústica & 65 & 21,17 \\
Sem declaração & 23 & 7,49 \\
\hline Total & 307 & 100,00 \\
\hline Cômodos & Média por domicílio & \\
\hline Total & 7,67 & \\
Dormitórios & 2,70 & \\
Banheiros & 1,89 & \\
\hline Condição de & & \\
ocupação & Número & \\
\hline Próprio já pago & 193 & 1,95 \\
Próprio em aquisição & 6 & 25,41 \\
Alugado & 78 & 0,65 \\
Cedido por & & 2,93 \\
empregador & 2 & 6,19 \\
Cedido por particular & 9 & 100,00 \\
Sem declaração & 19 &
\end{tabular}

Fonte: Do autor.

Observa-se que quanto ao tipo, a maioria dos domicílios são apartamentos, uma vez que Viçosa é um município bastante verticalizado em termos de construções, principalmente nas suas áreas mais centrais. Tais espaços são mais escassos e mais valorizados por estarem estrategicamente melhor localizados. Esse aspecto do município é destacado no estudo de Maria, Faria e Stephan (2014).

O domicílio médio da área urbana do município de Viçosa é composto por 7,67 cômodos, 2,70 dormitórios e 1,89 banheiros. Por esses dados, pode-se dizer que, em média, as residências são relativamente grandes, sendo que os resultados foram bastante próximos aos verificados pela POF 2005/2006. Considerando que a média na POF atual é de 2,77 moradores por domicílio com mediana 3, a disponibilidade de dormitórios e banheiros é adequada ao número de pessoas.

Em relação à condição de ocupação, nota-se que a maioria dos entrevistados já possui imóvel próprio (62,87\%) ou em processo de aquisição (1,95\%). Apenas 25,41\% pagam aluguel. 
Vale ressaltar que essa distribuição muito provavelmente não se verificaria em termos do destino das construções no município. Para a presente pesquisa, utilizou-se amostra coletada apenas em famílias residentes no município, não considerando a parte da população flutuante composta por estudantes. Certamente, parte significativa dos imóveis alugados no município é destinada a essa parcela da população.

A TAB. 7 apresenta a distribuição percentual dos entrevistados em termos da classificação da qualidade de serviços essenciais. Observa-se que para os cinco primeiros serviços apresentados, cuja responsabilidade é da Prefeitura Municipal de Viçosa, a porcentagem de bons foi próxima de $50 \%$, indicando que a qualidade e a disponibilidade dos mesmos carecem de melhorias significativas por parte do poder público responsável. Inclusive, a gestão feita por esse último em termos de oferecimento de tais serviços parece ter piorado nos últimos 15 anos, já que na POF 2005/2006 ${ }^{4}$, a porcentagem de bons foi bem superior, à exceção do escoamento da água de chuva, que já na referida POF, apresentara porcentagem de bons próxima à verificada na POF 2019/2020. Sobre esse ponto, conforme já alertado por Gomes (2006), a intensidade de chuvas anuais na região de Viçosa é elevada e por isso, o acúmulo da água de chuva representa transtornos para a população na forma de inundações e transmissão de doenças. A debilidade do serviço de captação pluvial e esgotos, principalmente nas áreas novas, habitadas por famílias de menor poder aquisitivo, é também destacada por Maria, Faria e Stephan (2014).

Tabela 7 - Distribuição percentual da amostra por opinião do entrevistado sobre a qualidade de serviços essenciais, POF 2019/2020, Viçosa, MG

\begin{tabular}{|c|c|c|c|c|c|c|}
\hline $\begin{array}{c}\text { Classificação/ } \\
\text { Serviço }\end{array}$ & Bom & Regular & Ruim & $\begin{array}{l}\text { Não } \\
\text { tem }\end{array}$ & $\begin{array}{c}\text { Sem } \\
\text { Declaração }\end{array}$ & Total \\
\hline $\begin{array}{c}\text { Fornecimento de } \\
\text { água }\end{array}$ & 51,14 & 31,27 & 9,77 & 0,98 & 6,84 & 100,00 \\
\hline $\begin{array}{c}\text { Serviços de água e } \\
\text { esgoto }\end{array}$ & 52,12 & 30,62 & 7,49 & 0,65 & 9,12 & 100,00 \\
\hline Coleta de lixo & 47,88 & 31,27 & 14,01 & 0,33 & 6,51 & 100,00 \\
\hline $\begin{array}{c}\text { Escoamento da água } \\
\text { de chuva }\end{array}$ & 47,56 & 21,82 & 19,22 & 4,56 & 6,84 & 100,00 \\
\hline Iluminação pública & 54,07 & 25,41 & 13,68 & 0,33 & 6,51 & 100,00 \\
\hline Energia elétrica & 75,24 & 13,03 & 5,21 & 0,00 & 6,51 & 100,00 \\
\hline
\end{tabular}

Apesar de haver espaços para importantes melhorias nos serviços prestados, deve-se destacar que a porcentagem de domicílios sem os referidos serviços é pequena. Em termos de

\footnotetext{
${ }^{4}$ Embora na POF 2005/2006, a porcentagem de sem declaração tenha sido comparativamente menor do que na POF 2019/2020, mesmo ao se ajustar esse ponto, a porcentagem de bons dessa última permanece bem inferior àquela verificada na primeira.
} 
qualidade, destaque para o serviço de energia elétrica, cujo fornecimento feito pela empresa responsável foi avaliado como bom por $75,24 \%$ dos entrevistados.

Por fim, foram feitas algumas perguntas sobre a condição de vida das famílias. Na TAB. 8, encontra-se a distribuição das opiniões dos entrevistados a respeito do grau de dificuldade para conciliar os gastos mensais com a renda disponível (orçamento), assim como a disponibilidade de alimentos no domicílio (alimentação).

Tabela 8 - Distribuição da amostra por opinião do entrevistado sobre o grau de dificuldade de administrar os gastos em conformidade com a renda disponível e sobre a disponibilidade de alimentos no domicílio, POF 2019/2020, Viçosa, MG

\begin{tabular}{|c|c|c|c|c|c|c|}
\hline $\begin{array}{c}\text { Classificação/ } \\
\text { Categoria }\end{array}$ & Dificuldade & $\begin{array}{c}\text { Alguma } \\
\text { Dificuldade }\end{array}$ & $\begin{array}{c}\text { Alguma } \\
\text { Facilidade }\end{array}$ & Facilidade & $\begin{array}{c}\text { Sem } \\
\text { Declaração }\end{array}$ & Total \\
\hline \multicolumn{7}{|l|}{ Orçamento } \\
\hline $\begin{array}{c}\text { Número } \\
\%\end{array}$ & $\begin{array}{c}66 \\
21,50\end{array}$ & $\begin{array}{c}82 \\
26,71\end{array}$ & $\begin{array}{c}67 \\
21,82\end{array}$ & $\begin{array}{c}75 \\
24,43\end{array}$ & $\begin{array}{c}17 \\
5,54\end{array}$ & $\begin{array}{l}307 \\
100\end{array}$ \\
\hline $\begin{array}{c}\text { Situação/ } \\
\text { Serviço }\end{array}$ & $\begin{array}{c}\text { Normalmente } \\
\text { insuficiente }\end{array}$ & $\begin{array}{c}\text { Às vezes } \\
\text { insuficiente }\end{array}$ & $\begin{array}{c}\text { Sempre } \\
\text { suficiente }\end{array}$ & $\begin{array}{c}\text { Sem } \\
\text { declaração }\end{array}$ & & Total \\
\hline \multicolumn{7}{|l|}{ Alimentação } \\
\hline $\begin{array}{c}\text { Número } \\
\%\end{array}$ & $\begin{array}{c}1 \\
0,33\end{array}$ & $\begin{array}{c}22 \\
7,17\end{array}$ & $\begin{array}{c}259 \\
84,36\end{array}$ & $\begin{array}{c}25 \\
8,14\end{array}$ & & $\begin{array}{l}307 \\
100\end{array}$ \\
\hline
\end{tabular}

Fonte: Do autor.

Em relação ao primeiro ponto, observa-se que cerca de metade dos entrevistados declararam ter algum tipo de facilidade para conciliar os gastos com a renda disponível enquanto a outra metade, afirmaram ter algum tipo de dificuldade. Apesar desse último ponto, de maneira geral, tem-se que as famílias viçosenses não apresentam inadimplência, já que quando perguntadas se elas nos últimos 12 meses atrasaram o pagamento do aluguel ou prestação da casa, das contas de água, luz ou telefone e das prestações de bens e serviços, as respostas foram negativas em $90,23 \%$, 80,46\% e 87,30\%, respectivamente.

Em relação à quantidade de alimentos consumidos pela família, a grande maioria respondeu que sempre há alimento suficiente em sua residência, sendo que apenas em 7,50\% das residências, há alguma deficiência em relação à quantidade de alimentos. Sobre esse ponto, a situação das famílias em Viçosa melhorou nos últimos 15 anos, já que na POF 2005/2006, tal número era de 20,23\%.

Passando agora para a estrutura da renda e dispêndios das famílias e domicílios de Viçosa-MG, a TAB. 9 fornece a distribuição da renda obtida pela amostra. A partir dessa última, é determinada a classe modal de renda, a qual será utilizada para obter a estrutura dos dispêndios da população-objetivo. 
Tabela 9 - Distribuição da amostra por grupos de renda familiar mensal, POF 2019/2020, Viçosa, MG

\begin{tabular}{cccc}
\hline Estratos de renda & \multirow{2}{*}{ Domicílios (No) } & \multicolumn{2}{c}{ Frequência (\%) } \\
\cline { 3 - 4 } (Salários-mínimos) & 11 & 3,58 & Acumulada \\
\hline 0 a 1 & 43 & 14,01 & 3,58 \\
1,01 a 2 & 46 & 14,98 & 17,59 \\
2,01 a 3 & 41 & 13,36 & 32,57 \\
3,01 a 4 & 22 & 7,17 & 45,93 \\
4,01 a 5 & 22 & 7,17 & 53,09 \\
5,01 a 6 & 18 & 5,86 & 60,26 \\
6,01 a 7 & 1 & 0,33 & 66,12 \\
7,01 a 8 & 15 & 4,89 & 66,45 \\
8,01 a 9 & 7 & 2,28 & 71,34 \\
9,01 a 10 & 20 & 6,51 & 73,62 \\
10,01 a 15 & 10 & 3,26 & 80,13 \\
Acima de 15 & 51 & 16,61 & 83,39 \\
Não respondeu & 307 & 100,00 & 100,00 \\
\hline Total & & & - \\
\hline
\end{tabular}

Fonte: Do autor.

Na definição da população-objetivo, utilizou-se o mesmo critério adotado em todas as POFs feitas em Viçosa, conforme apresentado por Gomes (2006). Segundo esse critério, dois pontos devem ser observados na população-objetivo: cobertura populacional e estabilidade da estrutura de consumo.

No quesito cobertura populacional, foi definida a cobertura de pelo menos $50 \%$ das famílias com chefes assalariados. Para obter a estabilidade da estrutura de consumo, utilizouse como regra excluir as famílias com rendimentos de até um salário-mínimo, com base no argumento de que esse segmento tem renda e estrutura de consumo instáveis ou atípicas.

Eliminando os domicílios com renda de até um salário-mínimo, nota-se que a populaçãoobjetivo, que representa a classe modal da pesquisa, é constituída pelas famílias com rendimento mensal de 1,01 a 6 salários-mínimos. Esse estrato de renda engloba 56,68\% da amostra, o que garante a representatividade exigida. Destaca-se que a classe modal da pesquisa atual (POF 2019/2020) não se alterou em relação àquela encontrada na última pesquisa realizada (POF 2005/2006).

A renda média das famílias da classe modal é de 3,09 salários-mínimos mensais. Na população fora da classe modal, a renda média é de 10,19 salários-mínimos. Para a amostra total, a renda média é de 5,37 salários-mínimos. Destaca-se que para as três categorias de análise, observou-se a média de 3 moradores por domicílio. 
Passando para a estrutura dos dispêndios, essa foi obtida agregando-se os gastos dos consumidores com os diversos produtos em itens, que, por sua vez, foram agregados em subgrupos, os quais irão constituir os grupos finais da cesta de consumo. Os dados apresentados na TAB. 10 permitem identificar as diferenças entre a composição dos grupos da classe modal e da amostra como um todo e se referem ao gasto médio total e por grupos de consumo do domicílio. No Anexo A, são apresentados para cada um dos 9 grupos de consumo, os seus subgrupos e itens ${ }^{5}$.

Tabela 10 - Composição dos gastos das famílias entrevistadas

\begin{tabular}{crrrrr}
\hline \multirow{2}{*}{ Grupo } & \multicolumn{2}{c}{ Classe Modal } & & \multicolumn{2}{c}{ Total } \\
\cline { 2 - 3 } \cline { 5 - 6 } & \multicolumn{1}{c}{$\mathbf{R}$} & \multicolumn{1}{c}{$\%$} & & $\mathbf{R} \$$ & \multicolumn{1}{c}{$\%$} \\
\hline Alimentação & 660,80 & 30,55 & & 682,73 & 27,29 \\
Vestuário & 71,97 & 3,33 & & 89,00 & 3,56 \\
Habitação & 723,91 & 33,46 & & 813,03 & 32,50 \\
Artigos de residência & 26,64 & 1,23 & & 32,43 & 1,30 \\
Transporte & 338,37 & 15,64 & & 436,27 & 17,44 \\
Comunicação & 16,71 & 0,77 & & 23,39 & 0,93 \\
Saúde/cuidados pessoais & 241,48 & 11,16 & & 293,95 & 11,75 \\
Educação & 37,03 & 1,71 & & 66,90 & 2,67 \\
Despesas pessoais & 46,48 & 2,15 & & 64,11 & 2,56 \\
\hline Total & $2.163,39$ & 100,00 & & $2.501,81$ & 100,00 \\
\hline
\end{tabular}

Fonte: Do autor.

É importante destacar que embora a ordenação dos grupos em termos de participação no orçamento das famílias seja praticamente a mesma para a classe modal e para o total da amostra, existem diferenças importantes na composição dos gastos quando se comparam essas duas categorias de análise. As famílias da classe modal consomem comparativamente mais no grupo Alimentação e Habitação, mas comparativamente menos nos grupos Transporte e Educação. Isso pode ser explicado pelo fato de que como o total da amostra considera estratos de renda mais elevados (acima de 6 salários mínimos), tal grupo tem um padrão de consumo diferenciado em relação à classe modal, destacando-se o fato de que aquele tende a ter maior acesso e, consequentemente, maior consumo de transporte particular (automóvel próprio e combustível) e educação particular. Além disso, por terem menores rendimentos, a parcela no orçamento referente aos produtos alimentícios e aos gastos com habitação tende a ser superior para a classe modal na comparação como o total da amostra. Destaca-se que esse panorama em relação aos gastos com alimentação foi idêntico ao verificado na última POF realizada em Viçosa (POF 2005/2006), cujos resultados completos são apresentados por Gomes (2006). A nível nacional, conforme IBGE (2020f), na POF 2017/2018 também se

\footnotetext{
${ }^{5} \mathrm{~A}$ descrição de todos os produtos para cada um dos itens, com as suas respectivas ponderações, está disponível em Cirino (2020).
} 
observou esse padrão em relação ao peso da alimentação e da habitação em termos de faixas de rendimento. Conforme a referida pesquisa, os dois grupos representaram $61,2 \%$ das despesas das famílias com menores rendimentos (até dois salários mínimos) e 30,2\% para aquelas com maiores rendimentos (acima de 25 salários mínimos).

A fim de comparar, entre a POF 2019/2020 e a POF 2005/2006, a participação no orçamento das famílias da classe modal para cada um dos grupos de consumo, é apresentada a TAB. 11, destacando-se que nas duas pesquisas, a referida classe abrange famílias com rendimentos de 1,01 a 6 salários mínimos.

Tabela 11 - Participação percentual no gasto total da classe modal para a POF 2019/2020 e a POF 2005/2006

\begin{tabular}{ccc}
\hline Grupo & POF 2020/2019 & POF 2005/2006 \\
\hline Alimentação & 30,55 & 27,25 \\
Vestuário & 3,33 & 5,40 \\
Habitação & 33,46 & 22,15 \\
Artigos de residência & 1,23 & 4,96 \\
Transporte & 15,64 & 11,93 \\
Comunicação & 0,77 & 5,41 \\
Saúde e cuidados pessoais & 11,16 & 15,55 \\
Educação & 1,71 & 3,95 \\
Despesas pessoais & 2,15 & 3,40 \\
\hline Total & 100,00 & 100,00 \\
\hline
\end{tabular}

Fonte: Do autor e Gomes (2006).

Um primeiro ponto a destacar é que revertendo a tendência de queda ao longo das três POFs anteriores realizadas em Viçosa, na POF atual, a participação do grupo Alimentação cresceu 3,30 pontos percentuais em relação à POF 2005/2006. Apesar disso, pela primeira vez, o referido grupo não é aquele de maior peso no orçamento total das famílias da classe modal, tendo sido ultrapassado pelo grupo Habitação, o qual foi aquele de maior aumento em termos de participação no gasto total (11,31 pontos percentuais em relação à POF 2005/2006). Outro grupo que apresentou aumento nesse sentido para a POF atual foi Transporte $(3,71$ pontos percentuais em relação à POF 2005/2006). Por outro lado, os grupos Vestuário, Artigos de Residência, Comunicação, Saúde e cuidados Pessoais, Educação e Despesas pessoais apresentaram redução na referida participação.

No que tange ao grupo Alimentação, o aumento na sua participação pode estar de certa forma associado à diversificação de produtos dessa natureza com a ampliação dos supermercados, restaurantes e redes de fast food, permitindo aos consumidores acesso a uma gama maior e mais variada de produtos alimentícios. A referida ampliação dos estabelecimentos comerciais citados foi impulsionada pela expansão da UFV por meio da 
criação de cursos e do oferecimento de mais vagas para estudantes nos cursos existentes a partir de meados dos anos 2000, em consonância com o Programa de Apoio a Planos de Reestruturação e Expansão das Universidades Federais (REUNI), conforme apontado por Maria, Faria e Stephan (2014) e Lopes (2011). No mesmo sentido, os referidos autores destacaram também o crescimento no período das instituições particulares de ensino superior localizadas em Viçosa. Ainda sobre a Alimentação, o aumento da participação desse grupo no gasto total das famílias vai ao encontro do maior acesso das mesmas aos produtos alimentícios, já que conforme apresentado, em 84,36\% dos domicílios entrevistados, a disponibilidade de alimentos foi sempre suficiente. Na comparação com a POF 2005/2006, tal valor fora de $78,61 \%$.

Em relação ao Grupo Habitação, destaca-se o aumento dos gastos das famílias da classe modal nos subgrupos Despesas com Moradia, com ênfase para os produtos acesso à internet, aluguel e TV por assinatura, e animais domésticos. Em relação a esse último subgrupo, desde a realização da POF 2005/2006, conforme destaca Poli (2016), verificou-se mudança no comportamento dos donos de animais de estimação, já que esses últimos passaram a viver dentro das casas e ganharam o status de membros da família. Por isso, passou-se a gastar muito mais com eles, inclusive passando os cuidados a serem muito mais preventivos do que curativos.

No que tange ao grupo Transporte, destaque para o aumento da participação do subgrupo Transporte Particular, tanto dentro do grupo como no gasto total. Esse resultado é reflexo do crescimento entre 2008 e 2019 da frota brasileira de carros e motos que aumentaram, respectivamente, $77 \%$ e 105\%, segundo relatório do Observatório das Metrópoles (2019).

Passando para os grupos que apresentaram redução na participação do gasto total entre as duas POFs, destaca-se o grupo Comunicação que foi aquele de maior redução (-4,64 pontos percentuais em relação à POF 2005/2006). Tal resultado é justificado por dois motivos. Primeiro pelo fato do produto Conta de telefone fixo residencial ter sido incluído no grupo Habitação na POF 2019/2020 (o que também de certa forma ajuda a explicar o aumento considerável desse grupo na POF atual), ao passo que na POF 2005/2006, o mesmo estava no grupo Comunicação. O segundo motivo está associado à substituição da importância do Telefone fixo residencial pelo Telefone celular, dado o crescimento da disponibilidade e uso desse último, inclusive pela possibilidade do seu uso gratuito através do aplicativo Whatsapp. Sobre esse ponto, destaca-se que enquanto na POF 2005/2006, o gasto médio da classe 
modal com Telefone fixo residencial era de $R \$ 105,14^{6}$, na POF atual o mesmo foi de $R \$ 25,28$. Fazendo-se a mesma comparação para o Telefone celular, o gastou passou de $\mathrm{R} \$ 17,14$ para $\mathrm{R} \$ 15,47$.

Alterando o foco de comparação para a POF 2019/2020 de Viçosa, que serve de base para o cálculo do IPC-Viçosa, com a POF 2017/2018 do Brasil, que fornece a ponderação para o IPCA, tem-se, respectivamente, os gráficos da Fig. 2.

Figura 2 - Composição dos gastos das famílias por grupos de consumo, IPC-Viçosa e IPCA

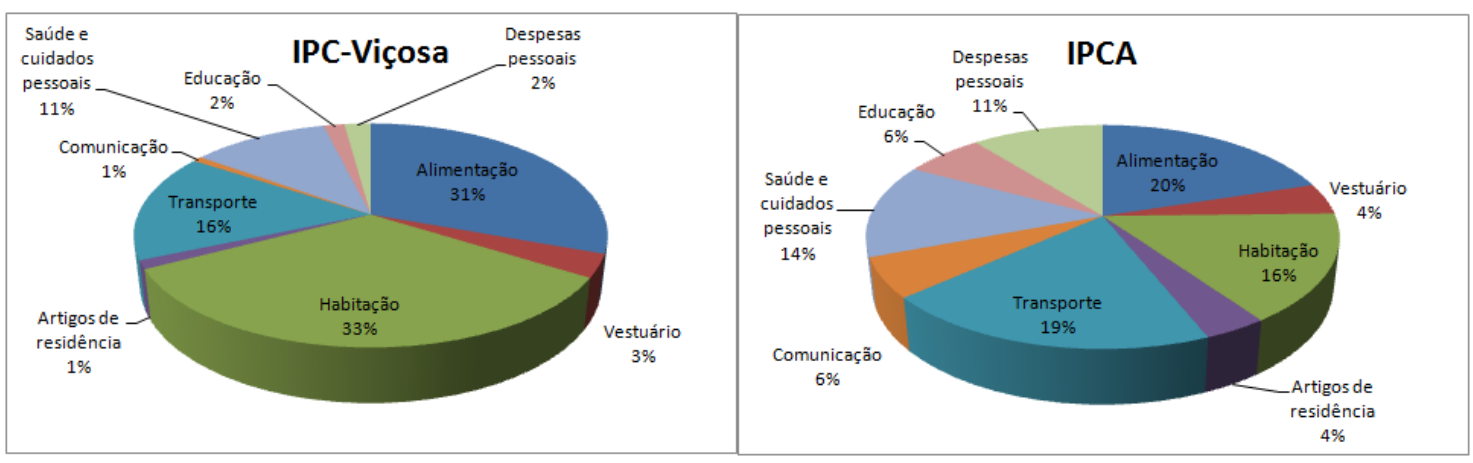

Fonte: Do autor e IBGE (2020c).

Em termos de similaridade, observa-se que os três grupos de maior participação no gasto total das famílias, embora não na mesma ordem, são: Habitação, Alimentação e Transporte. No entanto, conforme esperado, há diferenças marcantes na composição dos gastos familiares entre os dois índices, uma vez que os mesmos apresentam particularidades importantes.

O IPCA tem como população-objetivo famílias com rendimentos de 1 a 40 salários mínimos, sendo coletado nas seguintes regiões metropolitanas do Brasil: Belém, Fortaleza, Recife, Salvador, Belo Horizonte, Vitória, Rio de Janeiro, São Paulo, Curitiba, Porto Alegre, além do Distrito Federal e dos municípios de Goiânia, Campo Grande, Rio Branco, São Luís e Aracaju (IBGE, 2020d). Por outro lado, conforme já apontado no presente artigo, o IPC-Viçosa tem como população objetivo, famílias com rendimentos de 1,01 a 6 salários mínimos, sendo levantado exclusivamente para o município de Viçosa-MG.

Dessa forma, tanto a questão geográfica quanto a disparidade no limite superior de renda da população-objetivo entre os dois índices justificam as diferenças verificadas na composição dos gastos familiares para os grupos de consumo. Inclusive, o fato do peso no orçamento das famílias dos grupos Habitação e Alimentação serem, respectivamente, 17 e 11

\footnotetext{
${ }^{6}$ Valor corrigido para preços constantes de junho de 2019 conforme Índice de Preços ao Consumidor Amplo (IPCA) do IBGE.
} 
pontos percentuais maiores para o IPC-Viçosa na comparação com o IPCA, corrobora a importância da classe modal considerada em cada pesquisa. Isso porque quanto maior o rendimento, menor tende a ser a participação dos produtos alimentícios e dos gastos com moradia no orçamento familiar, liberando assim, recursos para serem gastos nos demais grupos de consumo.

Por fim, deve-se ressaltar que apesar das suas particularidades, os dois índices seguem a mesma tendência ao longo do tempo (Fig. 3).

Figura 3 - Valores anuais do IPCA e do IPC-Viçosa, 2006-2019

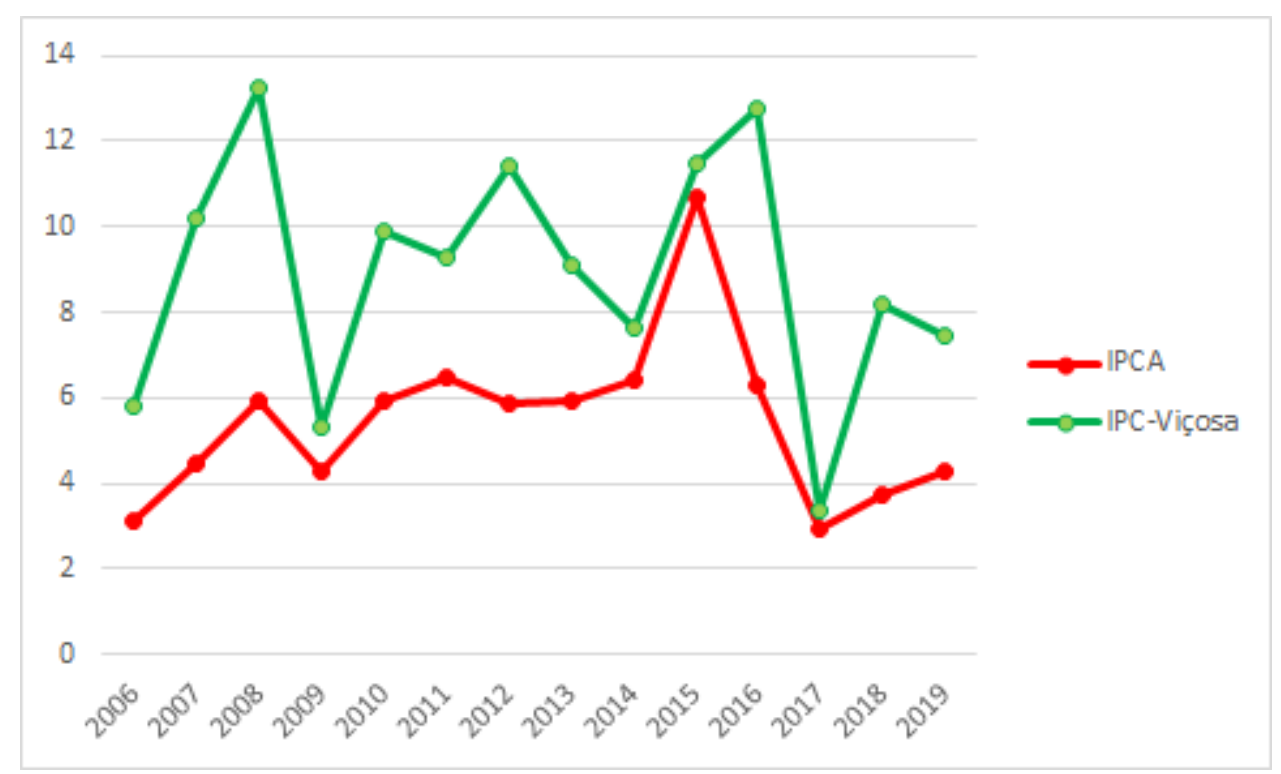

Fonte: DEE (2020) e IBGE (2020d).

Verifica-se que de maneira geral, quando o IPCA está subindo (descendo), o IPC-Viçosa também aumenta (diminui). Destaca-se que o valor do segundo foi superior ao observado para o primeiro em todo o período. É possível que tal comportamento seja reflexo de algumas especificidades da oferta e da demanda de bens e serviços no município.

Pelo lado da oferta, os maiores custos de transporte e a menor concorrência no mercado de Viçosa em comparação ao mercado nacional acabam fazendo com que as variações de preços sejam maiores no interior do que nas regiões onde o IPCA é levantado. Em relação ao primeiro ponto, adiciona-se o elevado preço dos combustíveis no município, os quais, constantemente, segundo dados da Agência Nacional do Petróleo, Gás Natural e Biocombustíveis (ANP) tem figurado entre os mais altos de Minas Gerais7. Tal fato faz com que os custos com transporte de pessoas e cargas fiquem mais caros. Com isso, caso esses sejam repassados,

7 De acordo com a mesma pesquisa, cujos dados estão disponíveis em ANP (2020), Minas Gerais constantemente figura entre os Estados brasileiros cujos preços dos combustíveis são os mais elevados. 
acabam tornando maiores as variações de preços dos produtos e serviços para o consumidor final, com possíveis impactos na taxa de inflação.

Esses fatores do lado da oferta são reforçados pela existência de uma demanda consolidada, uma vez que o município é um polo regional no fornecimento de bens e serviços para dezenas de outras localidades e uma cidade universitária cujo comércio e serviços estão fortemente voltados para o atendimento dos estudantes e dos profissionais diretos e indiretos da educação.

\section{CONCLUSÕES}

Para a manutenção de um índice de preços como o Índice de Preços ao Consumidor de Viçosa (IPC-Viçosa) é necessário que após determinado período de tempo, em virtude das alterações na cesta de consumo das pessoas, os gastos e a participação relativa de cada item na despesa total sejam atualizados. Essa atualização é feita por meio da Pesquisa de Orçamentos Familiares (POF).

Nesse sentido, o presente artigo teve como problema de pesquisa a apresentação dos principais resultados da POF 2019/2020, que foi uma pesquisa de obtenção de dados primários acerca das características socioeconômicas, dos domicílios e da estrutura de dispêndios e renda das famílias residentes no município de Viçosa, Minas Gerais.

Em termos de características socioeconômicas, no que tange à escolaridade, os dados confirmaram a vocação de cidade educadora de Viçosa, já que a maior parte dos entrevistados possuíam ensino médio completo ou ensino superior completo. Verificou-se também que a população no município é relativamente jovem, sendo que mais da metade das pessoas declararam idade inferior a quarenta e um anos.

Para as características dos domicílios, observou que eles são relativamente grandes, com média de aproximadamente oito cômodos para três habitantes por residência. Quanto ao tipo, a maioria dos domicílios são apartamentos, uma vez que Viçosa é um município bastante verticalizado em termos de construções, principalmente nas suas áreas mais centrais.

Quanto ao foco principal do estudo, que foi o levantamento da estrutura de dispêndios e renda no município, obteve-se classe modal compreendendo as famílias que possuíam renda mensal de 1,01 a 6 salários mínimos, as quais corresponderam a 56,68\% da amostra total. Por representar a cesta de consumo típica do cidadão viçosense, a ponderação para essa classe é a considerada no cálculo do IPC-Viçosa. 
O total de gastos com o consumo de bens e serviços declarados pelos entrevistados foram agrupados em grupos de consumo de forma que os três de maior peso no orçamento total das famílias da classe modal em Viçosa foram Habitação (33,47\%), Alimentação (30,54\%) e Transportes (15,64\%).

Conforme o esperado, as variações nos pesos dos grupos de consumo ocorridas entre a última POF (POF 2005/2006) e a POF atual (POF 2019/2020) justificam a necessidade de atualização periódica da cesta de consumo. Outro ponto a destacar foram as diferenças importantes entre os pesos da POF 2019/2020 de Viçosa e a POF 2017/2018 do Brasil, que serve de referência para o cálculo do Índice de Preços ao Consumidor Amplo (IPCA), cuja abrangência é nacional. Assim, justifica-se a criação, manutenção e atualização de um índice municipal de preços como o IPC-Viçosa, de forma a captar as particularidade locais da cesta de consumo e do comportamento dos preços dos bens e serviços.

Em termos de limitações, destaca-se a dificuldade para obter informações precisas de renda dos entrevistados, fato comum em pesquisas como a realizada, assim como dos gastos com bens e serviços. Sobre esse último ponto, uma vez que a gama dos produtos consumidos pelas famílias é bastante variada, o questionário era extenso, causando certo desgaste do entrevistado ao longo da pesquisa. Tal fato pode ter prejudicado a qualidade das informações, principalmente nos itens finais do questionário.

Por fim, destaca-se que a partir da realização da POF 2019/2020 obteve-se extensa base de dados que pode ser utilizada para pesquisas futuras sobre consumo, orçamento familiar e comportamento de preços que tenham de alguma forma, Viçosa como objeto de estudo. Ademais, os resultados da presente pesquisa, no que tange ao peso de cada produto nas despesas totais das famílias, podem ser utilizados pelos comerciantes e prestadores de serviços como indicativo das preferências dos consumidores viçosenses. Em termos de políticas públicas, os gestores municipais podem utilizar os resultados da piora, entre as duas últimas POF, no que tange à avaliação da população em relação aos serviços essenciais, para priorizar a melhoria no fornecimento dos mesmos.

\section{REFERÊNCIAS}

ANP - AGÊNCIA NACIONAL DO PETRÓLEO, GÁS NATURAL E BIOCOMBUSTÍVEIS. Sistema de levantamento de preços. Disponível em: <http://preco.anp.gov.br/>. Acesso em 5 set. 2020.

BCB - BANCO CENTRAL DO BRASIL. Índices de preço no Brasil. Série Perguntas mais frequentes. Brasília, mar. 2016. 
CAVENAGHI, Suzana; ALVES, José Eustáquio Diniz. Mulheres chefes de família no Brasil: avanços e desafios. Rio de Janeiro: ENS-CPES, 2018. 120 p.

CIRINO, Jader Fernandes (Coord.). IV Pesquisa de Orçamento Familiar em Viçosa - MG, 2019/2020 - Relatório Final: Viçosa, DEE/UFV, 2020. 97 p.

CIRINO, Jader Fernandes. Discriminação por gênero no mercado de trabalho: uma comparação do diferencial de rendimento entre homens e mulheres para os anos de 2002 e 2014. Planejamento e Políticas Públicas, Brasília, n. 51, p. 221-253, jul./dez. 2018.

CRUZ, Tancredo Almada (Coord.). Retrato Social de Viçosa V. Viçosa, MG: CENSUS, 2014. $91 \mathrm{p}$.

DEE - DEPARTAMENTO DE ECONOMIA. Boletim IPC. Disponível em: <http://www.dee.ufv.br/?page_id=500>. Acesso em: 03 abr. 2020.

GOMES, Adriano Provezano Gomes (Coord.). III Pesquisa de Orçamento Familiar em Viçosa - MG, 2005/2006 - Relatório Final: Viçosa, DEE/UFV, 2006. 69 p.

GOMES, Ana Paula Wendling; GOMES, Adriano Provezano. O comportamento dos preços em uma cidade do interior: o caso de Viçosa-MG. In: V Congresso de Ciências Humanas, Letras e Artes, 2001, Ouro Preto, MG, Anais... Ouro Preto, MG: UFOP, 2002.

GORLA, Marcello Christiano.; OLIVEIRA, Cosmo Rogério de; LAVARDA, Carlos Eduardo Facin. Análise crítica comparativa da utilização do IGPM e índices de preços setoriais para a tradução das demonstrações contábeis em moeda de valor constante. In: XVII Congresso Brasileiro de Custos, 2010, Belo Horizonte, Anais... São Leopoldo, RS: Associação Brasileira de Custos, 2010. Disponível em: < https://anaiscbc.emnuvens.com.br/anais/issue/view/4 >. Acesso em: 03 maio 2020.

HOFFMANN, Rodolfo. Estatística para economistas. 4⿳亠丷a Ed. São Paulo: Cengage Learning, 2006. $432 \mathrm{p}$.

HOFFMANN, Rodolfo; SIMÃO, Rosycler Cristina Santos. Determinantes dos rendimentos das pessoas ocupadas em Minas Gerais em 2000. Nova Economia, Belo Horizonte, v. 15, n. 2, p. 35-62, maio/ago. 2005.

IBGE - INSTITUTO BRASILEIRO DE GEOGRAFIA E ESTATÍSTICA. IBGE-Cidades. Disponível em: <https://cidades.ibge.gov.br/brasil/mg/vicosa/panorama>. Acesso em: 03 maio 2020a.

IBGE - INSTITUTO BRASILEIRO DE GEOGRAFIA E ESTATÍSTICA. Tábua completa de mortalidade para o Brasil - 2018: breve análise da mortalidade no Brasil. Rio de Janeiro: IBGE, 2019. 28 p.

IBGE - INSTITUTO BRASILEIRO DE GEOGRAFIA E ESTATÍSTICA. Pesquisa de Orçamentos Familiares - POF. Disponível em: <https://www.ibge.gov.br/estatisticas/sociais/educacao/9050-pesquisa-de-orcamentosfamiliares.html?=\&t=0-que-e $>$. Acesso em: 14 jul. $2020 \mathrm{~b}$. 
IBGE - INSTITUTO BRASILEIRO DE GEOGRAFIA E ESTATÍSTICA. SIDRA - Sistema Nacional de Índices de Preços ao Consumidor - SNIPC. Disponível em: <https://sidra.ibge.gov.br/pesquisa/snipc/ipca/quadros/brasil/junho-2020>. Acesso em: 18 jul. 2020c.

IBGE - INSTITUTO BRASILEIRO DE GEOGRAFIA E ESTATÍSTICA. Índice Nacional de Preços ao Consumidor Amplo - IPCA. Disponível em: <https://www.ibge.gov.br/estatisticas/economicas/precos-e-custos/9256-indice-nacional-deprecos-ao-consumidor-amplo.html?=\&t=0-que-e\&fbclid=IwAR0nNPYyvMURDdbM2xx2mFEPKSqxT1T2hxkfzbCrKtVgxtloiorZPuEph0>. Acesso em: 18 jul. 2020d.

IBGE - INSTITUTO BRASILEIRO DE GEOGRAFIA E ESTATÍSTICA. Agência IBGE Notícias. Disponível em: <https://agenciadenoticias.ibge.gov.br/agencia-sala-de-imprensa/2013-agenciade-noticias/releases/24857-pnad-continua-2018-educacao-avanca-no-pais-mas-desigualdadesraciais-e-por-regiao-

persistem\#: :text=Os\%20resultados\%20do\%20m\%C3\%B3dulo\%20de,e\%20ra\%C3\%A7a\%3A $\% 20$ mulheres\%20permaneciam\%20mais>. Acesso em: 3 set. 2020 e.

IBGE - INSTITUTO BRASILEIRO DE GEOGRAFIA E ESTATÍSTICA. Agência IBGE Notícias. Disponível em: <https://agenciadenoticias.ibge.gov.br/agencia-sala-de-imprensa/2013-agenciade-noticias/releases/25598-pof-2017-2018-familias-com-ate-r-1-9-mil-destinam-61-2-de-seusgastos-a-alimentacao-e-habitacao >. Acesso em: 4 set. $2020 f$.

JELIHOVSCHI, Enio. Análise Exploratória de dados usando o R. Ilhéus, BA: Editus, 2014. $84 \mathrm{p}$.

LOPES, Rodrigo de Mesquita Valladão. Análise do comportamento de preço ao consumidor: uma comparação do IPCA e do IPC-Viçosa. 35 f. Monografia (Bacharelado em Ciências Econômicas) - Departamento de Economia, Universidade Federal de Viçosa, Viçosa, MG, 2018.

LOPES, Vinicius Sales. O Plano Diretor do município de Viçosa-MG e a política de ordenamento territorial: avanços e limitações nas localidades de João Braz, Liberdade e Silvestre (2000 a 2010). 89 f. Monografia (Bacharelado em Geografia) - Departamento de Geografia, Universidade Federal de Viçosa, Viçosa, MG, 2011.

MARIA, Ana Cristina de Souza; FARIA, Teresa Cristina de Almeida; STEPHAN, Italo Itamar Caixeiro. Um retrato da evolução urbana de Viçosa-MG: impactos da federalização da UFV sobre a cidade (1969-2014). Revista Brasileira de Planejamento e Desenvolvimento, Curitiba, v. 3, n. 1, p. 37-54, jan./jul. 2014.

OBSERVATÓRIO DAS METRÓPOLES. Mapa da motorização individual no Brasil Relatório 2019. Rio de Janeiro: UFRJ/IPPUR, 2019. 27 p.

PNUD - PROGRAMA DAS NAÇÕES UNIDAS PARA O DESENVOLVIMENTO; FJP FUNDAÇÃO JOÃO PINHEIRO; IPEA - INSTITUTO DE PESQUISA ECONÔMICA APLICADA. Atlas do Desenvolvimento Humano no Brasil 2013. Disponível em: <http://atlasbrasil.org.br/2013/pt/>. Acesso em: 03 maio 2020. 
POLI, Mariana. Mercado pet cresce graças a mudanças no comportamento dos donos dos animais de estimação. Você S/A, São Paulo: Abril, edição 223, dez. 2016. Disponível em: $<$ https://vocesa.abril.com.br/geral/mercado-pet-cresce-gracas-a-mudancas-no-comportamentodos-donos-de-animais-de-estimacao/>. Acesso em: 22 maio 2020.

SICSÚ, Abraham Laredo; DANA, Samy. Estatística aplicada: análise exploratória de dados. São Paulo: Saraiva, 2012. 160 p.

SPERANDIO, Bruno. Conheça os principais índices de inflação do Brasil. Disponível em $<$ https://fiis.com.br/indices-de-inflacao/>. Acesso em: 03 maio 2020.

TAKAMATSU, Renata Turola; LAMOUNIER, Wagner Moura. A importância da atualização monetária de valores para a análise das demonstrações financeiras. Contabilidade Vista \& Revista, Belo Horizonte, v. 17, n. 2, p. 67-87, abr./jun. 2006.

TRICHES, Divanildo; FURLANETO, Aline Vanessa da Rosa. Anáise comparativa dos indicadores que medem a inflação na economia brasileira. Pesquisa \& Debate, São Paulo, v. 16, n. 1, p. 179-202, jan./jul 2005.

UNFPA - FUNDO DE POPULAÇÃO DAS NAÇÕES UNIDAS. Fecundidade e dinâmica da população brasileira. Brasília, Fundo de População das Nações Unidas no Brasil, 2018. 44 p.

UOL. Guia Economia - Inflação: entenda o que são os índices de inflação. Disponível em: <https://economia.uol.com.br/noticias/redacao/2019/12/22/o-que-sao-indices-de-inflacao.htm>. Acesso em: 22 dez. 2019.

VAN ZAIST, Juliana Kikuchi; NAKABASHI, Luciano; SALVATO, Márcio Antônio. Retornos privados de educação individual no Paraná. Economia, Brasília, v. 11, n. 1, p. 175-198, jan./abr. 2010. 
ANEXO A:

Tabela 1A - Estrutura do dispêndio das famílias com renda de 1,01 a 6 salários-mínimos.

Estratificação em grupos, subgrupos e itens de consumo - Grupo Alimentação, POF 2019/2020

\begin{tabular}{lccc}
\hline Especificação & Gasto $(\mathbf{R} \$)$ & \% do grupo & \% do total \\
\hline 1. Alimentação & 680,80 & 100,00 & 30,55 \\
1.1. Alimentação no domicílio & & & \\
1.1.01. Carnes bovinas & 613,95 & 92,91 & 28,38 \\
1.1.02. Carnes suínas & 77,51 & 11,73 & 3,59 \\
1.1.03. Carnes de aves e ovos & 28,63 & 4,33 & 1,32 \\
1.1.04. Pescados & 52,94 & 8,01 & 2,45 \\
1.1.05. Carnes processadas & 10,57 & 1,60 & 0,49 \\
1.1.06. Cereais, leguminosas e oleaginosas & 28,42 & 4,30 & 1,31 \\
1.1.07. Frutas & 54,45 & 8,24 & 2,52 \\
1.1.08. Leite e derivados & 55,78 & 8,44 & 2,58 \\
1.1.09. Óleos e gorduras & 62,60 & 9,47 & 2,89 \\
1.1.10. Hortaliças e verduras & 26,29 & 3,98 & 1,22 \\
1.1.11. Tubérculos, rázes e legumes & 10,22 & 1,55 & 0,47 \\
1.1.12. Farinhas e féculas & 44,00 & 6,66 & 2,03 \\
1.1.13. Massas & 15,01 & 2,27 & 0,69 \\
1.1.14. Doces, chocolates e açucares & 22,32 & 3,38 & 1,03 \\
1.1.15. Panificados & 30,93 & 4,68 & 1,43 \\
1.1.16. Enlatados e conservas & 28,34 & 4,29 & 1,31 \\
1.1.17. Sal e condimentos & 14,73 & 2,23 & 0,68 \\
1.1.18. Bebidas não alcoólicas & 9,93 & 1,50 & 0,46 \\
1.1.19. Bebidas alcoólicas & 28,52 & 4,32 & 1,32 \\
1.2. Alimentação fora do domicílio & 12,76 & 1,93 & 0,59 \\
1.2.01. Refeição & & & \\
1.2.02. Bebidas não alcoólicas & 46,85 & 7,09 & 2,17 \\
1.2.03. Bebidas alcoólicas & 28,34 & 4,29 & 1,31 \\
1.2.04. Lanches & 2,32 & 0,35 & 0,11 \\
Fonte Do aur. & 9,87 & 1,49 & 0,46 \\
& 6,32 & 0,96 & 0,29 \\
\hline
\end{tabular}

Fonte: Do autor.

Tabela 2A - Estrutura do dispêndio das famílias com renda de 1,01 a 6 salários-mínimos. Estratificação em grupos, subgrupos e itens de consumo - Grupo Vestuário, POF 2019/2020

\begin{tabular}{lccc}
\hline \multicolumn{1}{c}{ Especificação } & Gasto $(\mathbf{R} \mathbf{\text { ) }}$ & \% do grupo & \% do total \\
\hline 2. Vestuário & 71,97 & 100,00 & 3,33 \\
2.1. Artigos de confecção & 46,61 & 64,76 & 2,16 \\
2.1.01. Roupas de criança & 10,48 & 14,56 & 0,48 \\
2.1.02. Roupas de mulher & 17,94 & 24,92 & 0,83 \\
2.1.03. Roupas de homem & 18,19 & 25,28 & 0,85 \\
2.2. Calçados e acessórios & 19,19 & 26,67 & 0,89 \\
2.2.01. Calçados & 15,63 & 21,72 & 0,73 \\
2.2.02. Acessórios & 3,56 & 4,95 & 0,16 \\
2.3. Tecidos e aviamentos & 0,72 & 0,99 & 0,03 \\
2.4. Artigos de cama, mesa e banho & & & 0,25 \\
\hline Fonte: Do autor & 5,46 & 7,58 &
\end{tabular}

Fonte: Do autor. 
Tabela 3A - Estrutura do dispêndio das famílias com renda de 1,01 a 6 salários-mínimos. Estratificação em grupos, subgrupos e itens de consumo - Grupo Habitação, POF 2019/2020

\begin{tabular}{lccc}
\hline Especificação & Gasto (R\$) & \% do grupo & \% do total \\
\hline 3. Habitação & 723,91 & 100,00 & 33,46 \\
3.1. Moradia & 540,40 & 74,65 & 24,99 \\
3.2. Reforma e manutenção & 56,77 & 7,84 & 2,62 \\
3.2.01. Artigos de jardinagem & 0,23 & 0,03 & 0,01 \\
3.2.02. Material hidráulico & 2,73 & 0,38 & 0,13 \\
3.2.03. Material elétrico & 3,73 & 0,51 & 0,17 \\
3.2.04. Ferragens & 1,49 & 0,21 & 0,07 \\
3.2.05. Material de pintura & 3,12 & 0,43 & 0,14 \\
3.2.06. Material de construção & 5,46 & 0,75 & 0,25 \\
3.2.07. Mão-de-obra & 40,01 & 5,53 & 1,85 \\
& & & \\
3.3. Serviços domésticos & 31,68 & 4,38 & 1,46 \\
3.4. Material de limpeza e uso doméstico & 34,41 & & \\
3.4.01. Material de limpeza & 31,26 & 4,75 & 1,59 \\
3.4.02. Uso doméstico & 3,15 & 4,32 & 1,44 \\
3.5. Animais domésticos & 60,66 & 0,43 & 0,15 \\
3.5.01. Manutenção de animais & 60,66 & 8,38 & 2,80 \\
3.5.02. Compra de animais & 00,00 & 8,38 & 2,80 \\
\hline Fonte. Do autor. & & 0,00 & 0,00 \\
\hline
\end{tabular}

Fonte: Do autor.

Tabela 4A - Estrutura do dispêndio das famílias com renda de 1,01 a 6 salários-mínimos. Estratificação em grupos, subgrupos e itens de consumo - Grupo Artigos de Residência, POF 2019/2020

\begin{tabular}{lccc}
\hline Especificação & Gasto (R\$) & \% do grupo & \% do total \\
\hline 4. Artigos de residência & 26,64 & 100,00 & 1,23 \\
4.1. Mobiliário e acessórios & 10,99 & 41,25 & 0,51 \\
4.1.01. Móveis de sala & 6,16 & 23,14 & 0,29 \\
4.1.02. Móveis de quarto & 4,17 & 15,64 & 0,19 \\
4.1.03. Móveis de copa e cozinha & 0,66 & 2,47 & 0,03 \\
4.1.04. Móveis de escritório & 0,00 & 0,00 & 0,00 \\
4.1.05. Móveis externos & 0,00 & 0,00 & 0,00 \\
4.2. Equipamentos eletrônicos & 4,14 & 15,54 & 0,19 \\
4.3. Eletrodomésticos & & & 0,25 \\
& 5,41 & 20,31 & 0,28 \\
4.4. Utensílios domésticos & 6,10 & 22,90 & 0,24 \\
4.4.01. Utensílios de cozinha & 5,09 & 19,10 & 0,04 \\
4.4.02. Outros utensílios & 1,01 & 3,80 & 0,00 \\
4.5. Consertos e manutenção & 0,00 & 0,00 & \\
\hline
\end{tabular}

Fonte: Do autor. 
Tabela 5A - Estrutura do dispêndio das famílias com renda de 1,01 a 6 salários-mínimos. Estratificação em grupos, subgrupos e itens de consumo - Grupo Transporte, POF 2019/2020

\begin{tabular}{lccc}
\hline Especificação & Gasto (R\$) & \% do grupo & \% do total \\
& & & 100,00 \\
\hline 5. Transporte & 338,37 & & 15,64 \\
& 35,82 & 10,59 & 1,66 \\
5.1. Transporte coletivo & 10,60 & 7,13 & 0,49 \\
5.1.01. Transporte intermunicipal & 25,22 & & 1,17 \\
5.1.02. Transporte Urbano & & 89,41 & 13,98 \\
5.2. Transporte particular & 302,55 & 60,37 & 9,44 \\
5.2.01. Aquisição de veículos próprios & 204,27 & 25,83 & 4,04 \\
5.2.02. Combustíveis e taxas & 87,42 & 3,21 & 0,50 \\
\hline 5.2.03. Manutenção e reparos & 10,86 & &
\end{tabular}

Fonte: Do autor.

Tabela 6A - Estrutura do dispêndio das famílias com renda de 1,01 a 6 salários-mínimos. Estratificação em grupos, subgrupos e itens de consumo - Grupo Comunicação, POF $2019 / 2020$

\begin{tabular}{lccc}
\hline Especificação & Gasto (R\$) & \% do grupo & \% do total \\
\hline 6. Comunicação & 16,71 & 100,00 & 0,77 \\
6.1. Telefone & 15,48 & 92,61 & 0,72 \\
6.2. Correio & 1,24 & 7,39 & 0,05 \\
6.3. Outros & 0,00 & 0,00 & 0,00 \\
\hline
\end{tabular}

Tabela 7A - Estrutura do dispêndio das famílias com renda de 1,01 a 6 salários-mínimos. Estratificação em grupos, subgrupos e itens de consumo - Grupo Saúde e Cuidados Pessoais, POF 2019/2020

\begin{tabular}{lccc}
\hline Especificação & Gasto (R\$) & \% do grupo & \% do total \\
\hline 7. Saúde e cuidados pessoais & 241,48 & 100,00 & 11,16 \\
& & & \\
7.1. Remédios e produtos farmacêuticos & 60,35 & 24,99 & 2,79 \\
7.1.01. Remédios & 58,50 & 24,23 & 2,70 \\
7.1.02. Curativos e outros & 1,85 & 0,76 & 0,09 \\
7.2. Higiene e cuidados pessoais & 45,77 & 18,95 & 2,12 \\
7.2.01. Higiene da boca & 14,07 & 5,83 & 0,65 \\
7.2.02. Produtos para cabelo & 13,45 & 5,57 & 0,62 \\
7.2.03. Mãos e unhas & 0,59 & 0,24 & 0,03 \\
7.2.04. Cosméticos & 11,17 & 4,63 & 0,52 \\
7.2.05. Barba & 3,09 & 1,28 & 0,14 \\
7.2.06. Higiene íntima & 3,40 & 1,41 & 0,16 \\
7.3. Assistência à saúde & & & \\
7.3.01. Assistência Médica & 65,67 & 27,19 & 3,04 \\
7.3.02. Assistência Odontológica & 23,45 & 9,71 & 1,09 \\
\hline
\end{tabular}


Continuação.

Continua...

\begin{tabular}{lccc}
\hline Especificação & Gasto $(\mathbf{R} \$)$ & \% do grupo & \% do total \\
\hline 7.3.03. Assistência Hospitalar e laboratorial & 11,41 & 4,73 & 0,53 \\
7.4. Outros gastos & 69,70 & 28,87 & 3,21 \\
\hline
\end{tabular}

Fonte: Do autor.

Tabela 8A - Estrutura do dispêndio das famílias com renda de 1,01 a 6 salários-mínimos. Estratificação em grupos, subgrupos e itens de consumo - Grupo Educação, POF 2019/2020

\begin{tabular}{lccc}
\hline Especificação & Gasto (R\$) & \% do grupo & \% do total \\
\hline 8. Educação & 37,03 & 100,00 & 1,71 \\
8.1. Mensalidades e taxas escolares & 34,57 & 93,35 & 1,60 \\
& & & \\
8.2. Material escolar & 2,46 & 6,65 & 0,11 \\
8.2.01. Livros, revistas e similares & 0,06 & 0,17 & 0,00 \\
8.2.02. Artigos de papelaria & 2,40 & 6,48 & 0,11 \\
\hline
\end{tabular}

Fonte: Do autor.

Tabela 9A - Estrutura do dispêndio das famílias com renda de 1,01 a 6 salários-mínimos. Estratificação em grupos, subgrupos e itens de consumo - Grupo Despesas Pessoais, POF $2019 / 2020$

\begin{tabular}{lccc}
\hline Especificação & Gasto (R\$) & \% do grupo & \% do total \\
\hline 9. Despesas pessoais & 46,48 & 100,00 & 2,15 \\
9.1. Serviços pessoais & 22,28 & 47,93 & 1,03 \\
& & & \\
9.2. Lazer e esportes & 17,03 & 36,64 & 0,79 \\
9.2.01. Cds, vídeos e similares & 2,61 & 5,62 & 0,12 \\
9.2.02. Material esportivo e clubes & 11,36 & 24,44 & 0,53 \\
9.2.03. Brinquedos e similares & 0,41 & 0,89 & 0,02 \\
9.2.04. Outros gastos com lazer & 2,64 & 5,69 & 0,12 \\
9.3. Outras despesas pessoais & & & \\
9.3.01. Fumo & 7,17 & 15,43 & 0,33 \\
9.3.02. Jogos e apostas & 5.06 & 10,88 & 0,23 \\
9.3.03. Leitura & 0,80 & 1,73 & 0,04 \\
9.3.04. Joias e bijuterias & 0,83 & 1,78 & 0,04 \\
9.3.05. Outros produtos pessoais & 0,16 & 0,35 & 0,01 \\
F. Doutor & 0,32 & 0,69 & 0,01 \\
\hline
\end{tabular}

Fonte: Do autor. 